\title{
ANAESTHETIC CONSIDERATIONS IN IDIOPATHIC ORTHOSTATIC HYPOTENSION AND THE SHY-DRAGER SYNDROME
}

\author{
M.D. Mal,an and R.R. Crago
}

THE anaesthetic MaNagement of patients with idiopathic orthostatic hypotension has been detailed in only one case report' which became the basis for the only other discussion of this condition in the anaesthetic literature. ${ }^{2}$ Since then, the understanding of this condition has greatly increased, although there remains confusion concerning the nosology, the site of the defect, and the best form of treatment. There is sufficient agreement regarding the cardiovascular reflexes and response to vasoactive agents to be able to formulate a rational basis of anaesthetic management. We present one case of idiopathic orthostatic hypotension to illustrate the anaesthetic management.

Orthostatic hypotension is the major feature of autonomic failure which may occur in association with widespread neurological disease (ShyDrager syndrome ${ }^{3,4}$ ), in association with idiopathic parkinsonism, or as an isolated disturbance, idiopathic orthostatic hypotension..$^{5-7}$ It is the autonomic failure that makes these conditions so challenging to the anaesthetist. The other causes of orthostatic hypotension are readily excluded, such as cardiac failure, diminished circulating blood volume, drug therapy, neurologic causes such as Wernicke's encephalopathy, tabes dorsalis, surgical sympathectomy, the neuropathies of diabetes, amyloidosis and the Guillain-Barré syndrome. Adie's syndrome of the myotonic pupil which is rarely associated with orthostatic hypotension and familial dysautonomia or the Riley-Day syndrome, which is associated with labile pressure and hypertension, have to be differentiated from idiopathic orthostatic hypotension.9 Anaesthesia for patients with familial dysautonomia has been reviewed by Meridy and Creighton. ${ }^{10}$

The features of idiopathic orthostatic hypoten-

M.D. Malan, B.Sc. (Med.), M.B., Ch.B., Resident, Department of Anaesthesia. University of Toronto, Toronto Western Hospital, Toronto, Ontario.

R.R. Crago, B.Sc., M.D., F.R.C.P.(C), Assistant Professor. Department of Anaesthesia, University of Toronto, Toronto Western Hospital, Toronto, Ontario.

Address reprint requests to: R.R. Crago. Toronto Western Hospital, 399 Bathurst Street, Toronto, Ontario, Canada, M5T 2S8.

Canad. Anaesth. Soc. J., vol. 26, no. 4, July 1979 sion are due to autonomic failure as a result of lesions in the central and efferent sympathetic pathway, ${ }^{9}$ caused by a degeneration of pigmented brain stem nuclei, loss of sympathetic intermediolateral column cells in the spinal cord and varying degrees of ganglionic and post-ganglionic degeneration. The primary defect appears to be cellular loss, " but in some cases there may be an element of peripheral nervous dysfunction, as there is evidence that in some patients the sympathetic failure is a result of depletion of norepinephrine stores from efferent nerve endings. ${ }^{12}$ The integrity of the adrenergic receptors is not in doubt. ${ }^{14}$ Both the sympathetic and the parasympathetic systems are involved. 9 The defect in the sympathetic vasomotor system may be patchy, so that in the same vascular bed some vessels might be affected while others escape the deficiency. ${ }^{13}$

The most important effect on the cardiovascular system is the disturbance of the baroreceptor reflex, due to defect of the eentral or efferent pathways, resulting in defective vasoconstriction of both the resistance and capacitance vessels. " Although difficult to assess when the defect is in the efferent limb, the afferent baroreceptor mechanism appears intact. ${ }^{14}$ Using the cold pressor test to provide an alternate afferent input and to evaluate the central and efferent elements, the normal rise in blood pressure is not seen. The mental arithmetic test evaluates the same components. Measurement of blood pressure, cardiac output and peripheral resistance on a tilt table provides further assessment of the extent of the disorder. Another test of the cardiovascular reflexes is the performance of the Valsalva manosuvre; the normal tachycardia and blood pressure overshoot after this mancuvre are not usually seen. A further feature is the disorder of vagal and sympathetic control of the heart rate, so that the heart rate is relatively fixed. The results reported in the literature from infusions of vasoac. tive drugs such as norepinephrine, isoproterenol or phenylephrine, while important in an individual case, are not consistent. ${ }^{13.15}$ This is because some patients do not show the exaggerated response characteristic of denervation hypersen- 
sitivity. Patients with idiopathic orthostatic hypotension show more evidence of denervation sensitivity than do patients with the Shy-Drager syndrome. ${ }^{3.12,13}$ An infusion of tyramine may fail to raise the blood pressure. Tyramine acts by releasing peripheral stores of norepinephrine. In the absence of adequate stores there will be no incjease in blood pressure with a tyramine infusion. Atropine may produce no increase in heart rate if there is reduced resting parasympathetic tone. The physidlogical basis of these tests has been reviewed. ${ }^{14}$

The tests discussed above are important to delineate the extent of the disorder and to provide important information on which to base decisions regarding the conduct of anaesthesia and the choice of agents and ancillary vasoactive drugs. Measurement of plasma catecholamines, dopamine beta hydroxylase, renin, angiotension and urinary catecholamine degradation products provide clinically less important information. ${ }^{7.16 .17}$

Other autonomic functions may also be impaired. Salivation and sweating may be reduced, sphincter disturbance and impotence are common, and there may be reduced ocular reflexes. It is important to note these as some signs of the depth of anaesthesia, such as sweating and pupillary changes, may not be available in these patients. ${ }^{2}$

Treatment is rarely completely satisfactory and does not affect the disease itself. ${ }^{8}$ In an attempt to increase catecholamine production in the pigmented brain stem nuclei and other sites in the central nervous system, levodopa and MAO inhibitors have been administered with some success. ${ }^{16.18}$ Some success has been achieved by liberating peripheral stores of norepinephrine either with amphetamines ${ }^{19}$ or tyramine, ${ }^{15}$ by limiting metabolism with MAO inhibitors or by direct stimulation with ephedrine or phenylephrine. ${ }^{6}$ Symptomatic control of the orthostatic hypotension can be achieved by using the potent mineralocorticoid 9- $\alpha$-fluorohydrocortisone to increase blood volume. ${ }^{8}$ Pooling in the legs can be reduced by elastic bandaging. The development of oedema, hypertension or frank cardiac failure limits these approaches. The use of indometha$\operatorname{cin}^{17}$ has been advocated to control the hypotension, although the mode of action is unclear. ${ }^{20}$ The management of the other aspects of the autonomic failure follow symptomatic lines, examples being increased bulk for constipation, urecholine for urinary retention and active cooling for fever.

Preoperative preparation thus involves inves- tigation of the extent of the disorder and an attempt to establish optimal function of the cardiovascular system.

\section{CAse Report}

A 42-year-old man weighing $80 \mathrm{~kg}$ was presented for nasal polypectomy, septoplasty and ethmoid antrostomy for recurring nasal polyps. He had a nine-year history of progressive widespread involvement of the autonomic nervous system, having suffered from impotence, urinary retention, constipation, dry mouth, poor sweating. heat intolerance, postural syncope, reduced exercise tolerance and classic angina pectoris.

Twenty months before this admission he was fully investigated and the diagnosis of idiopathic orthostatic hypotension was made. The orthostatic hypotension was severe, with blood pressure $18.6 / 10.6 \mathrm{kPa}(140 / 80 \mathrm{~mm} \mathrm{Hg})$ lying and $8.0 / ? \mathrm{kPa}(60 / ? \mathrm{~mm} \mathrm{Hg})$ standing, with no change in the heart rate of 80 per minute. Examination of the nervous system showed some ptosis on the left but no evidence of peripheral neuropathy. cerebellar or extrapyramidal involvement. Sweating was confined to the right axilla. Investigations including routine haemotology, biochemistry, venereal disease research laboratory test for syphilis, glucose tolerance, chest $X$-ray and nerve conduction were normal. Rectal biopsy showed no amyloid. Barium enemil showed a dilated colon and the rectal motility study showed low resting internal sphincter pressure with intact reflex responses. The Valsalva manceuvre produced hypotension without rebound hypertension or tachycardia. The cold pressor and mental arithmetic tests were negative indicating a defect in the central or efferent pathways. Tilting to 60 degrees produced profound hypotension, a 60 per cent reduction in cardiac output and no change in heart rate.

Infusion of norepinephrine and isoproterenol showed hypersensitivity of both $\alpha$ - and $\beta$ receptors. Tyramine injection produced a very slight response, indicating that a reduced amount of norepinephrine was available at sympathetic nerve endings. Atropine $1.2 \mathrm{mg}$ produced no tachycardia, indicating no resting vagal tone. Following the investigation, treatment with fluorocortisone $0.1 \mathrm{mg}$ three times daily was started. with marked improvement. and this was continued up to the time of the operation.

Preoperatively his blood pressure was 20.0/ $13.3 \mathrm{kPa}(150 / 100 \mathrm{~mm} \mathrm{Hg})$ lying and $13.3 / 8.0 \mathrm{kPa}$ $(100 / 60 \mathrm{~mm} \mathrm{Hg})$ standing, with pulse rate fixed 
at 80 per minute. Routine investigations were normal except for repolarization changes and indeterminate axis on the electrocardiogram and a lowered serum potassium which was corrected with increased potassium intake. He had not had a syncopal episode for one year, but had angina pectoris with exercise. Stress testing revealed a $4 \mathrm{~mm}$ ST depression at Bruce level IV with the onset of angina. Direct intra-arterial blood pressure measurement showed a drop from $16.0 / 10.6 \mathrm{kPa}(120 / 80 \mathrm{~mm} \mathrm{Hg})$ standing to $10.6 / 2.7 \mathrm{kPa}(80 / 20 \mathrm{~mm} \mathrm{Hg})$ at an exercise level that evoked his angina.

Premedication was with diazepam $10 \mathrm{mg}$ orally and morphine $10 \mathrm{mg}$ and cortisone acetate $100 \mathrm{mg}$ by intramuscular injection. The surgeon was asked to avoid the local use of norepinephrine or cocaine due to the uncertain effects on blood pressure.

Intensive monitoring during operation was considered to be most important. This monitoring included continuous direct intra-arterial blood pressure measurement, electrocardiogram lead V5, blood gas analysis, oesophageal temperature and a peripheral nerve stimulator. Two large bore intravenous cannulae were placed. Infusions of dopamine, metaraminol and sodium nitroprusside were prepared.

Anaesthesia was induced slowly with incremental doses of diazepam to a total of $30 \mathrm{mg}$ and fentanyl citrate to $300 \mu \mathrm{g}$ with 50 per cent nitrous oxide in oxygen. Relaxation and intubation were achieved with pancuronium bromide $6 \mathrm{mg}$ and $160 \mathrm{mg}$ of topical xylocaine hydrochloride. An Air Shields ventilator was adjusted to deliver 10 breaths per minute of $800 \mathrm{ml}$ each. After stabilization, halothane one half per cent was added to the fresh gas flow of 67 per cent nitrous oxide in oxygen at 6 litres per minute. Hydrocortisone $100 \mathrm{mg}$ was given intravenously during the procedure. Reversal of anaesthesia was achieved by discontinuing the nitrous oxide and halothane and by the administration of neostigmine $3.5 \mathrm{mg}$, atropine $1.5 \mathrm{mg}$ and naloxone $0.2 \mathrm{mg}$.

Blood pressure on arrival in the operating room was $22.6 / 13.3 \mathrm{kPa}(170 / 100 \mathrm{~mm} \mathrm{Hg})$ and subsequent to arterial cannulation it was 26.6/ $14.6 \mathrm{kPa}(200 / 110 \mathrm{~mm} \mathrm{Hg})$ by cuff and transducer. The induction of anaesthesia was very smooth with the blood pressure steady at $21.3 / 13.3 \mathrm{kPa}(160 / 100 \mathrm{~mm} \mathrm{Hg})$. With the addition of halothane one half per cent to the inspired gases the blood pressure dropped, over fifteen minutes, to $12.0 / 8.0 \mathrm{kPa}(110 / 60 \mathrm{~mm} \mathrm{Hg})$ where it remained until the halothane was stopped, when it rose over twenty minutes to the preoperative level. The patient tolerated $20^{\circ}$ head up tilt with no change in blood pressure after fluid loading with $1500 \mathrm{ml}$ of balanced salt solution. Pulse rate was $60-70$ per minute throughout the procedure. The blood gases during operation were $\mathrm{Pa}_{2}$ $17.82 \mathrm{kPa}$ ( 134 torr), $\mathrm{Pa}_{\mathrm{CO}_{2}} 5.32 \mathrm{kPa}$ (40 torr) and $\mathrm{cH}^{+} 36.31 \mathrm{nmol} / \mathrm{l}(\mathrm{pH} 7.44)$. The temperature was stable and the electrocardiogram remained normal throughout the procedure. There was no need to administer either a vasopressor or a hypotensive agent. The duration of anaesthesia was 75 minutes.

The patient recovered consciousness and had complete control of his airway within a short time. Blood pressure remained at $21.3 / 12.0 \mathrm{kPa}$ ( $160 / 90 \mathrm{~mm} \mathrm{Hg}$ ) and pulse rate dropped from 90 to 75 per minute over the next two hours. Prior to discharge to the floor he had a mild respiratory acidosis with $\mathrm{cH}^{+} 42.66 \mathrm{nmol} / \mathrm{l}(\mathrm{pH} 7.37)$. $\mathrm{Pa}_{\left(\mathrm{Ca}_{2}\right.}$ $6.18 \mathrm{kPa}$ (46.5 torr) and $\mathrm{Pa}_{\mathrm{u}_{2}} 12.24 \mathrm{kPa}$ (92 torr) breathing room air. The subsequent course was uneventful.

\section{Discussion}

This patient had well documented autonomic failure with severe orthostatic hypotension that responded well to symptomatic treatment, including fluorohydrocortisone. The cardiovascular reflexes were absent, there was some degree of sympathetic denervation sensitivity and there was disordered control of heart rate. The diagnosis of idiopathic orthostatic hypotension (isolated autonomic dysfunction or isolated autonomic failure) ${ }^{5}$ was made because of the absence of parkinsonian, cerebellar or extrapyramidal signs.

Based on his preoperative evaluation we were able to predict the responses to anaesthesia and to choose agents and techniques appropriately. Premedication was with morphine and diazepam, a combination well known to produce minimal cardiovascular effects. The induction of anaesthesia had to be accomplished with minimal depression of cardiac output, cardiac slowing or vasodilatation to avoid profound hypotension. Thus diazepam, fentanyl and pancuronium were used for the induction of anaesthesia. The agents chosen are noted for their minimal effect on the cardiovascular system. ${ }^{21}$ Maintenance of anaesthesia was complicated because of absent signs of the depth of anaesthesia, possible sensitivity to potent volatile agents and the need to have an awake patient at the end of a short procedure 
TABLE I

Aspects OF ANAESTheTIC IMPORTANCE IN IDIOPATHIC ORTHOSTATIC HYPOTENSION

\begin{tabular}{ll}
\hline \multicolumn{1}{c}{ Feature } & \multicolumn{1}{c}{ Anaesthetic Considerations } \\
\hline $\begin{array}{l}\text { Disordered baroreceptor reflex } \\
\text { Defective vasoconstriction }\end{array}$ & $\begin{array}{l}\text { Labile blood pressure. } \\
\text { Postural hypotension. Sensitivity to reduced blood volume, vasodilators, } \\
\text { cardiac depressants. } \\
\text { Hefective heart rate control } \\
\text { anaesthesia. }\end{array}$ \\
Hypotension & $\begin{array}{l}\text { Fluids and posture to infuence central blood volume. Direct } \alpha \text { stimulants for } \\
\text { defective vasoconstriction. Consider dopamine or isoproterenol for chronow } \\
\text { tropic and inotropic effects. }\end{array}$ \\
Poor sweating & Hyperpyrexia: monitor temperature. Loss of a sign of anaesthesia. \\
Pupillary reflexes & May be sluggish. Loss of a sign of anaesthesia. \\
Parasympathetic deficiency & Atropine may not increase heart rate. \\
Response to vasoactive agents & $\begin{array}{l}\text { Diminished, notmal or exaggerated responses to indirect and direct acting } \\
\text { agents. Direct acting agents preferred. Preoperative response noted. }\end{array}$ \\
Control of respiration & May be disordered. \\
Preoperative drug therapy & Standard considerations for patients taking sympathomimetics, MAOI's, or \\
& steroids.
\end{tabular}

involving the upper airway. We decided to introduce halothane in low concentration and, if necessary, to withdraw it and continue with intravenous agents. This was not necessary.

Factors reducing venous return such as intermittent positive pressure ventilation (IPPV), head up tilt and generalised vasodilatation would result in hypotension that should respond to fuid loading and postural changes such as elevation of the legs. Reduction of cardiac output would result in hypotension; this could be managed by attention to the venous return, myocardial depression and the cautious use of a direct myocardial stimulant such as dopamine. Bradycardia may be a factor in producing hypotension. While drug induced bradycardia should respond to atropine, it may be necessary to use isoproterenol or even direct pacing. Relaxation of the resistance vessels resulting in hypotension should respond to withdrawal of the vasodilator and the cautious use of a direct acting $\alpha$-adrenergic stimulator such as phenylephrine or metaraminol. The maintenance of preoperative hydration and the possibility of steroid dependence in patients treated with 9- $\alpha$-fluorohydrocortisone must be considered preoperatively.

Because of the absent cardiovascular reflexes, abrupt changes of blood pressure were expected with anaesthesia, especially at induction. Thus it was important to monitor both the blood pressure and the electrocardiogram continuously and to be able to restore blood volume rapidly. The place- ment of an intravenous catheter to measure cen. tral venous pressure is mandatory, and in some cases a flotation catheter to measure pulmonary artery wedge pressure would be necessary to manage the hypotension appropriately.

The choice of vasopressor should be based on awareness that the stores of norepinephrine at the nerve endings may be absent or reduced, and that response to adrenergic agents may be reduced or exaggerated. We chose, but had no need to use. metaraminol, a short-acting and mainly directacting sympathomimetic with predominantly $\alpha$ effects. In addition, blood pressure may have to be reduced because of an unpredictable hypertensive response to a vasopressor. A short-acting drug that is independent of the adrenergic system, like nitroprusside, ${ }^{21}$ is the hypotensive agent of choice. The monitoring of temperature is important, because reduced sweating may lead to hyperpyrexia. Abnormal responses to muscle relaxants may be seen. ${ }^{2}$ There is one case report of sleep apnoea syndrome associated with the Shy-Drager syndrome and the possibility of a central disorder of the control of respiration may need to be considered. ${ }^{22}$ Table I summarizes the anaesthetic problem areas.

Thus the successful administration of anaesthesia in idiopathic orthostatic hypotension involves comprehensive preoperative evaluation with special reference to the cardiovascular reflexes and the response to vasoactive drugs. Complex drug interactions may have to be con- 
sidered. Because the normal mechanisms which compensate for changes caused by operation and anaesthesia are absent, the anaesthetist will be called upon to provide this homeostasis by the application of the basic concepts of cardiovascular physiology in the face of abnormal autonomic responses.

\section{SUMMARY}

Orthostatic hypotension due to autonomic failure may occur secondary to systemic disease states (notably diabetes) or as a disease entity in its own right with a variable degree of neurological involvement that has resulted in a confused classification. The diagnosis, classification and treatment of these latter forms of orthostatic hypotension is reviewed. The pathology is in the central and efferent autonomic pathway, resulting in a disordered baro-receptor reflex, postural hypotension, abnormal responses to tilling and the Valsalva manouvre, an inappropriately fixed heart rate and other autonomic features. Anaesthesia may be associated with profound hypotension and some of the signs of anaesthesia may be absent. The response to cardiac depressant drugs and reduction of circulating blood volume may be exaggerated due to absence of compensatory mechanisms. The response to vasoactive agents is unpredictable. The importance of preoperative evaluation, monitoring during operation and the careful selection of anaesthetic agents and techniques is discussed.

\section{RÉSUMÉ}

La dysfonction du système nerveux autonome avec hypotension orthostatique peut étre primaire avec une atteinte neurologique variable ou secondaire à une atteinte systémique (le diabète est souvent en cause). Cet article présente la classification, le diagnostic et le traitement de la forme primaire. La pathologie du SNA se situe au niveau central et efférent avec atteinte des réflexes barorécepteurs et hypotension posturale, une réponse anormale aux mancuvres de Valsalva et de "tilting", une fréquence cardiaque fixe et d'autres manifestations neuro-végétatives. Des épisodes d'hypotension grave sont susceptibles de se produire sous anesthésie et certains signes d'anesthésie peuvent ètre absents. Les effets des agents dépresseurs du myocarde et ceux de l'hypovolémie peuvent être exagérés par absence des mécanismes compensateurs. Les effets des vasopresseurs peuvent être imprédicti- bles. L'évaluation pré-opératoire, le monitoring adéquat et le choix judicieux des agents et des techniques d'anesthésie sont des aspects importants chez ces malades.

\section{ACKNOWLEDGEMENTS}

The authors are grateful to Dr. P. Ashby and to the Cardiovascular Unit at the Toronto Western Hospital. The manuscript was prepared by Mrs. I. Bell.

\section{REFERENCES}

1. CoHeN, C.A. Anaesthetic management of a paticn with the Shy-Dragersyndrome. Anesthesiology 35 95-97(1970).

2. KATZ, I. \& KaDis, L.B. Anaesthesita and uncommon diseases. First edition. Philadelphia: Saunders (1973). p. 400.

3. Shy, G.M. \& Drager, G.A. A neurologic syndrome associated with orthostatic hypotension. Arch. Neurol. 2: $511 \rightarrow 527$ (1960)

4. Bannister, R. \& OpPenheiater, D.R. Degenerative diseases of the nervous system associaled with autonomic failure. Brain 95; $457-474$ (1972).

5. Bannister, R., Davies, B. \& Sever, P. Indomethacin for Shy-Drager syndrome. Lancet $I$ : 1312 (1978).

6. Davies, B., Bannister, R. \& Sever, P. Pressor amines and monoamine oxidase inhibitors for treatment of postural hypotension in autonomic failure. Lancet $t: 172-175$ (1978)

7. Ziegler, M.G., LAKe, C.R. \& KopiN. I.J. The sympathetic-nervous-system defect in primary orthostatic hypotension. N. Engl. J. Med. 296: 293-297(1977).

8. Plum, F. in Beeson, P.B. \& McDermott, W Textbook of Medicine, 14th ed. Philadelphia: Saunders, p. 645 (1975).

9. BANNister, $R$. Degeneration of the autonomic nervous systen. Lancet 2: 175-179 (1971).

10. Meridy, H.W. \& Creighton, R.E. General anaesthesia in eight patients with familial dysautonomia. Can. Anaesth. Soc. J. 18: 563 (1971)

11. Bannister, R., Sever, P. \& Gross, M. Car diovascular reflexes and biochemicat responses in progressive autonomic failure. Brain 100: 327-344 (1977).

12. Kontos H A Richardonon, D.W \& Norvel J.E. Norepinephrine depletion in idiopathic orthostatic hypotension. Ann. Intern. Med. 82 336-341 (1975)

13. - Mechanisms of circulatory dysfunction in orthostatic hypotension. Trans. Am. Clin. Climatal. Assoc. 87: 26-35 (1975).

14. Irrahis, M.M. Localization of lesion in patients with idiopathic orthostatic hypotension. Br. Heart J. $37: 868-872$ (1975)

15. Diamond, M.A., Murray, R.H. \& Schmid, P.G. ldiopathic postural hypotension: physiologic observations and report of a new mode of therapy. $J$. Clin. Invest. 49: 1341-48 (1970).

16. Sharpe, J., Marquez-Julio, A. \& Ashby, P. 
Idiopathic orthostatic hypotension treated with levodopa and MAO inhibitor: a preliminary report. Can. Med. Assoc. J. 107: 296-300 (1972).

17. KochaR, M.S. \& Itskovitz, H.D. Treatment of idiopathic orthostatic hypotension (Shy-Drager syndrome) with indomethacin. Lancet $1: 1011$ (1978).

18. Thomas, J.E. \& Schirger, A. Idiopathic orthostatic hypotension. Arch. Neurol. 22: 289-293 (1970).

19. SELLER, R.H. Idiopathic orthostatic hypotension: a report of successful treatment with a new form of therapy. Am. J. Cardiol. 23: 838-844 (1969).

20. Gullner, H.G. Indomethacin for Shy-Drager syndrome. Lancet $l: 1312$ (1978).

21. VICKERS, M.D., WOOD-SMiTH, F.G. \& STEWART H.C. Drugs in Anaesthetic Practice, 5th ed. Butterworths (1978).

22. Lehrman, K.L., Gullleminault, C. SchroeDER. J.S., TILKIAN, A. \& Forno, L.N. Sleep apnoea syndrome in a patient with Shy-Drager syndrome. Arch. Intern. Med. 138: 206-209(1978). 